\title{
Anisomycin infused into the hippocampus fails to block "reconsolidation" but impairs extinction: The role of re-exposure duration
}

\author{
Ann E. Power, 1,3,4 Daniel J. Berlau, 2,3 James L. McGaugh,, 2,3 and Oswald Steward ${ }^{1,2,3}$ \\ ${ }^{1}$ Department of Anatomy and Neurobiology and Reeve-Irvine Research Center, ${ }^{2}$ Department of Neurobiology and Behavior, \\ and ${ }^{3}$ Irvine Center for the Neurobiology of Learning and Memory, University of California-Irvine, Irvine, California 92697, USA
}

Recent studies have reported new evidence consistent with the hypothesis that reactivating a memory by re-exposure to a training context destabilizes the memory and induces "reconsolidation." In the present experiments, rats' memory for inhibitory avoidance (IA) training was tested 6 h (Test 1), $2 \mathrm{~d}$ (Test 2), and $6 \mathrm{~d}$ (Test 3) after training. On Test 1 the rats were either removed from the shock compartment immediately after entry or retained in the shock context for $200 \mathrm{sec}$, and intrahippocampal infusions of the protein synthesis inhibitor anisomycin (75 $\mathrm{gg} / \mathrm{side})$ were administered immediately after the test. Anisomycin infusions administered after Test 1 impaired IA performance on Test 2 in animals given the brief re-exposure, but impaired extinction in animals exposed to the context for $200 \mathrm{sec}$. Rats with anisomycin-induced retention impairment on Test 2 demonstrated spontaneous recovery of retention performance on Test 3, whereas rats showing extinction on Test 2 showed further extinction on Test 3. The findings indicate that post-retrieval administration of anisomycin impairs subsequent retention performance only in the absence of extinction and that this impairment is temporary.

Extensive evidence indicates that memories are initially labile and then gradually become stabilized or consolidated (McGaugh 1966, 2000). Memory consolidation can be enhanced or impaired by treatments administered during this post-training labile phase (McGaugh 2000; McIntyre et al. 2003). It is wellestablished that consolidation can be blocked by administration of protein synthesis inhibitors (e.g., Davis and Squire 1984; Barrientos et al. 2002). Several recent studies reporting that postretrieval drug treatments, including protein synthesis inhibitors, impair subsequent retention performance have provided evidence suggesting that memory retrieval may trigger a new phase of memory lability, termed "reconsolidation" (Przybyslawski and Sara 1997; Nader et al. 2000; Debiec et al. 2002). These studies have revived an earlier debate concerning the stability of consolidated memory traces (Misanin et al 1968; Schneider and Sherman 1968; Dawson and McGaugh 1969; DeVietti and Holliday 1972; Lewis 1979; Mactutus et al. 1979). Recent experiments investigating the reconsolidation hypothesis have, like the earlier ones, produced conflicting findings concerning the experimental conditions required for producing post-retrieval retention performance impairment as well as the permanence of the impairment, when obtained (Sara 2000; Berman and Dudai 2001; Vianna et al. 2001; Anokhin et al. 2002; Kida et al. 2002; Milekic and Alberini 2002; Bahar et al. 2003, 2004; Koh and Bernstein 2003; Biedenkapp and Rudy 2004; Cammarota et al. 2004b; Duvarci and Nader 2004; Fischer et al. 2004; Lattal and Abel 2004). These varying results suggest that there may be highly specific conditions under which post-retrieval treatments either do or do not impair subsequent retention performance (Dudai 2004; McGaugh 2004).

Learning and retrieval both activate hippocampal circuits (Sara 2000; Debiec et al. 2002), activate molecular pathways including MAP kinase (Kelly et al. 2003), and induce expression of

\footnotetext{
${ }^{4}$ Corresponding author.

E-mail apower@uci.edu; fax (949) 824-9272.

Article and publication are at http://www.learnmem.org/cgi/doi/10.1101/ Im.91206.
}

immediate early genes (Bozon et al. 2003; Strekalova et al. 2003). Advocates of the reconsolidation hypothesis suggest that these similarities support the view that retrieval induces a recapitulation of the original consolidation processes (Nader 2003). However, differences in the molecular processes occurring during new memory consolidation and memory reactivation during retrieval have also been reported (Taubenfeld et al. 2001; Bahar et al. 2004; Lattal and Abel 2004; Lee et al. 2004; Salinska et al. 2004; Suzuki et al. 2004; Alberini 2005). These molecular discrepancies together with the inconsistent behavioral findings suggest that the relationship between retrieval and consolidation is more complicated than the reconsolidation hypothesis implies.

It is also difficult to reconcile the reconsolidation hypothesis with the classical prediction that re-exposure to conditioned stimuli (CS) in the absence of the unconditioned stimulus (US) should produce a new, presumably protein synthesis-dependent, memory that provides the basis for extinction (Pavlov 1927; McGaugh 2000; Bouton 2004). Extinction appears to engage many of the same consolidation mechanisms as those engaged by acquisition of an association (Berman and Dudai 2001; Vianna et al. 2001, 2003; Lin et al. 2003; Sangha et al. 2003; Cammarota et al. 2004a; Santini et al. 2004). However, pharmacological studies have also reported finding differences in the effects of drugs on the development of an association and its extinction (Berman and Dudai 2001; Bahar et al. 2003; Lin et al. 2003; Fischer et al. 2004; Lattal et al. 2004; Mingote et al. 2004; Suzuki et al. 2004).

Thus, this study investigated whether the protein-synthesisdependent processes initiated by re-exposure to the training environment involve reactivation of the training memory or new extinction learning. Rats were trained in an inhibitory avoidance (IA) task and, $6 \mathrm{~h}$ later, given intrahippocampal infusions of anisomycin or vehicle following a retention test in the training context. Brief and extended testing procedures were tested. If retrieval induces memory trace lability and initiates reconsolidation, then anisomycin infused into the hippocampus following either a brief or an extended re-exposure to the training context should impair subsequent memory. Alternatively, post-retrieval 
anisomycin infusions after an extended re-exposure may impair the consolidation of a newly acquired extinction memory rather than the avoidance memory. Additionally if post-retrieval retention impairment is due to impairment of memory reconsolidation, then memory should not return either spontaneously or after a weak reminder shock.

\section{Results}

Experiment 1A: Post-retrieval impairment of inhibitory avoidance retention performance

As illustrated in Figure 1A, rats given intrahippocampal anisomycin (Fig. 3, below) after brief re-exposure to the IA context $6 \mathrm{~h}$ after training exhibited impaired retention performance when retested $2 \mathrm{~d}$ later (ANOVA $F_{4,75}=10.34 ; P<0.001$ ). The key comparisons are on Test 2, when the effects of the re-exposure trial should be manifest. Importantly, the training and Test 1 entrance latency data indicate that the groups had comparable IA acquisition. The groups' mean entrance latencies during training did not differ (post-Test 1 vehicle: $17.4 \pm 2.1 \mathrm{sec}$; post-Test 1 anisomycin: $18.4 \pm 1.7 \mathrm{sec}$; and no Test 1 anisomycin: $19.9 \pm 1.3 \mathrm{sec} ; \mathrm{Ps}>0.05)$. On Test 1 , the vehicle- and anisomycin-treated groups' avoidance latencies were significantly longer than the training entrance latencies $(P s<0.001)$ but not different from one another (post-Test 1 vehicle: $303 \pm 71 \mathrm{sec}$; post-Test 1 anisomycin: $333 \pm 70 \mathrm{sec}$ ). The latencies observed with this shock intensity and duration were consistent with those reported in previous studies of the post-retrieval retention impairment effect in the IA task (Milekic and Alberini 2002).

Rats given anisomycin infusions after Test 1 had impaired retention performance at Test $2(154 \pm 20 \mathrm{sec} ; P<0.05)$ compared to their own performance at Test 1 and the performance of vehicle-infused rats at Test $2(320 \pm 61 \mathrm{sec} ; P<0.05)$. Their mean entrance latency at Test 2, however, remained greater than that at training $(P<0.05)$, indicating that although anisomycin impaired later retention performance, it did not produce complete amnesia. The similar mean retention latencies for vehicle-infused rats at Tests 1 and $2(P>0.05)$ indicate that the re-exposure procedure used in Experiment 1 did not produce any measurable extinction in the vehicle controls.

The retention performance at Test $2(352 \pm 56 \mathrm{sec})$ of rats that were given anisomycin $6 \mathrm{~h}$ after training but were not given a Test 1 re-exposure to the training context was not different from either the Test 1 performance of vehicle-treated and anisomycin-treated rats or the Test 2 performance of vehicle-treated rats $(P \mathrm{~s}>0.05)$. Therefore, the impaired retention seen in the anisomycin-treated rats at Test 2 was not due to the anisomycin infusion alone, but rather depended on the re-exposure to the training context at Test 1 . These results are comparable to those typically found in studies examining post-retrieval retention performance impairment with longer (1-2 d) intervals between training and re-exposure.

\section{Experiment 1B: Spontaneous recovery and savings}

Rats in Experiment 1B exhibited the same anisomycin-induced retention impairments in Test 2 that were observed in Experiment $1 \mathrm{~A}$ (ANOVA $F_{4,50}=1.118, P<0.001$ ), but also demonstrated that the memory impairment was temporary, as anisomycin-treated rats demonstrated spontaneous recovery of retention performance at Test 3 given $6 \mathrm{~d}$ after the training (Fig. 1B). The groups' training latencies did not differ (post-Test 1 vehicle: $20.6 \pm 3.3 \mathrm{sec}$; post-Test 1 anisomycin: $22.4 \pm 2.3 \mathrm{sec}$ ). At Test 1 , the entrance latencies were significantly longer than the training entrance latencies (post-Test 1 vehicle: $P<0.05$; post-Test 1 anisomcyin: $P<0.001$; vs. training) but not different from each

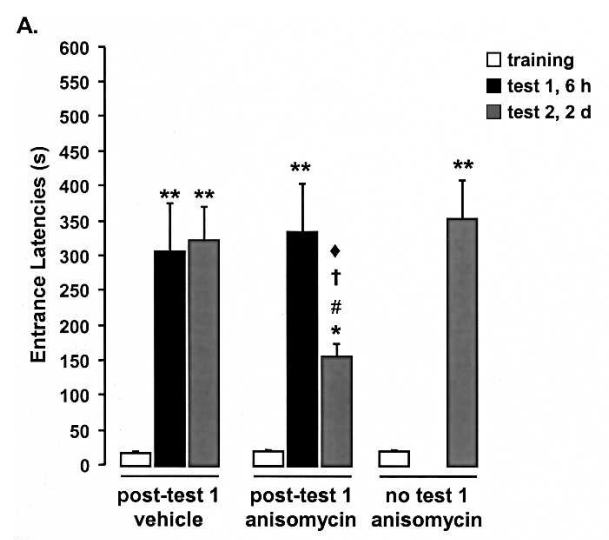

B.

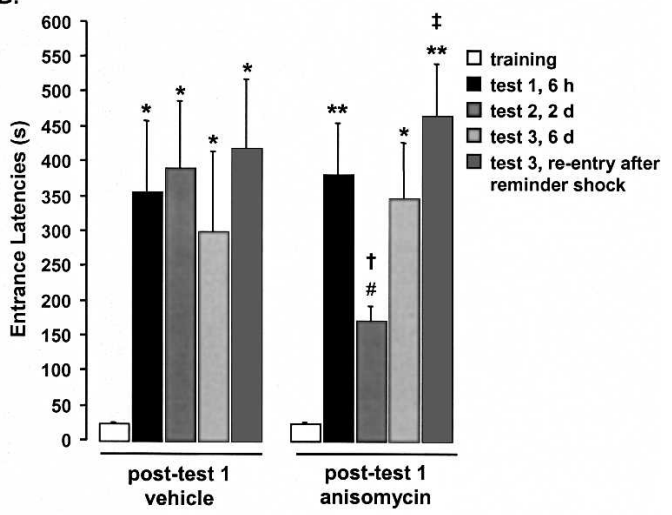

c.

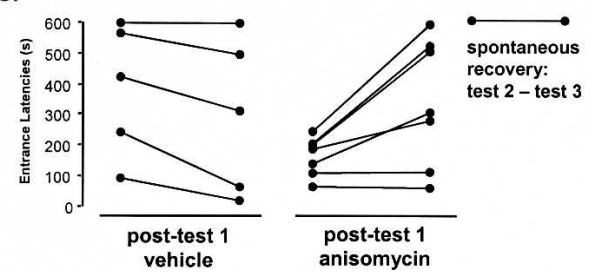

Figure 1. Brief re-exposure inhibitory avoidance behavior. Rats in Experiments $1 \mathrm{~A}$ and $1 \mathrm{~B}$ were removed from the shock compartment immediately after entering it on the test days. Data are given as groups' mean latencies to cross into the shock context at each trial. (A) All groups learned to avoid the dark shock compartment $\left[\left(^{*}\right) P<0.05,\left({ }^{* *}\right) P<0.001\right.$ vs. training]. Vehicle controls did not show extinction. Post-Test 1 anisomycin treatment decreased avoidance at Test $2[(\#) P<0.05$ vs. Test 1 within group, $(\dagger) P<0.05$ vs. vehicle within trial, $(\diamond) P<0.05$ vs. no Test 1 group within trial]. Anisomycin treatment in the absence of context re-exposure at Test 1 did not affect retention. $(B)$ The avoidance learning $\left[\left(^{*}\right) P<0.05,\left(^{* *}\right) P<0.001\right.$ vs. training], lack of extinction in vehicle controls, and anisomycin-induced retention impairment at Test 2 were replicated in Experiment $1 \mathrm{~B}[(\#) P<0.05$ vs. Test 1 within group, ( $\dagger$ ) $P<0.05$ vs. vehicle within trial]. Test $3,6 \mathrm{~d}$ after training, revealed a spontaneous recovery of retention performance in anisomycin-treated rats $(P>0.05$ vs. Test 1 and vs. vehicle within trial). A mild reminder shock following spontaneous recovery elevated avoidance latency well above the impaired level observed at Test $2[(\ddagger) P<0.05$ vs. Test 2 within group]. (C) Spontaneous memory recovery by individual rats between Test 2 and Test 3 (before the reminder shock). Five of the seven anisomycin-infused rats in Experiment 1B showed greater avoidance indicative of spontaneous recovery of memory between Test 2 and Test 3 . No vehicle-infused rats showed greater avoidance at Test 3 than at Test 2.

other (post-Test 1 vehicle: $351 \pm 104 \mathrm{sec}$; post-Test 1 anisomycin: $378 \pm 75 \mathrm{sec})$. Rats given anisomycin infusions after Test 1 had impaired retention performance at Test $2(168 \pm 24 \mathrm{sec}$; $P<0.05)$ compared to their own performance at Test 1 and the performance of vehicle-infused rats at Test 2 (386 \pm 97 sec; $P<0.05)$. 
Contrary to the prediction of the reconsolidation hypothesis that the anisomycin-induced impairment should be permanent, anisomycin-treated rats demonstrated a notable spontaneous recovery of retention performance at Test 3 (Fig. 1B). That is, the anisomycin-treated rats' avoidance behavior during Test 3 ( $345 \pm 79 \mathrm{sec}$ before and $461 \pm 77 \mathrm{sec}$ after reminder shock) was no longer impaired relative to vehicle controls $(298 \pm 115$ sec before and $415 \pm 100 \mathrm{sec}$ after reminder shock; Ps $>0.05$ ). The mean magnitude of recovery (Test 3 before reminder shock - Test 2) in the anisomycin-treated rats was $177 \pm 57$ sec. Meanwhile, the entrance latencies of vehicle controls exhibited a minor (nonsignificant) decrease between Test 2 and Test 3 (mean change $-88 \pm 30 \mathrm{sec}$ ).

The distribution of latencies for the individual rats at Test 3 (Fig. 1C) was similar to that observed at Test 1 . That is, those rats that had relatively high or low latencies at Test 1 also had high or low latencies, respectively, at Test 3 . As a result, the spontaneous recovery is most pronounced in those rats that exhibited long latencies before the drug treatment and not evident in the two rats that consistently exhibited shorter latencies.

The reminder shock did increase the avoidance latencies of anisomycin-treated rats (Test 3 after reminder shock vs. Test 2; $P<0.05)$. This finding provides evidence of savings. However, their previous exhibition of spontaneous recovery before the reminder shock had already indicated that there was intact memory in the anisomycin-treated rats.

\section{Experiment 2: Post-retrieval blockade of inhibitory avoidance extinction}

The key question addressed in Experiment 2 was whether infusing anisomycin into the hippocampus after a longer re-exposure to the training context, one that supports extinction, would lead to impaired IA memory 2 d later, as predicted by the reconsolidation hypothesis, or whether new extinction learning would be impaired. As shown in Figure 2, anisomycin given after the extended context re-exposure procedure blocked extinction (ANOVA $F_{8,125}=9.72 ; P<0.001$ ). As in Experiment 1 , the key comparisons are in Test 2 . However, it is important to demonstrate comparable IA learning between the groups as well as the expected extinction with the prolonged exposure procedure. All groups in Experiment 2 demonstrated comparable IA learning (Fig. 2A). This is evidenced by the findings that the mean entrance latencies during training did not differ among the groups (post-Test 1 vehicle: $19.2 \pm 1.2 \mathrm{sec}$; post-Test 1 anisomycin: $21.5 \pm 1.2 \mathrm{sec}$; no Test 1 anisomycin: $21.7 \pm 1.4 \mathrm{sec} ; P \mathrm{~s}>0.05)$ and that both the vehicle- $(390 \pm 60 \mathrm{sec})$ and anisomycintreated (393 $\pm 59 \mathrm{sec})$ groups had Test 1 avoidance latencies that were longer than the training entrance latencies $(P \mathrm{~s}<0.001)$, but not different from each other $(P>0.05)$.

Extinction with the extended context re-exposure was observed in vehicle-treated rats as evidenced by a shorter mean entrance latency at Test $2(193 \pm 6 \mathrm{sec})$ than at Test 1 , as well as by a shorter mean entrance latency at Test $3(52.7 \pm 13 \mathrm{sec})$ than at Test $2(P \mathrm{~s}<0.05)$ (Fig. $2 \mathrm{~A})$. Critically, however, the mean entrance latency at Test $2(373 \pm 52 \mathrm{sec})$ for the post-Test 1 anisomycin-treated rats did not differ from the latency at Test 1 $(P>0.05)$. This post-Test 1 anisomycin group demonstrated subsequent extinction in the absence of the drug between Test 2 and Test $3(137 \pm 27 \mathrm{sec} ; P<0.001)$. This result indicates that the anisomycin treatment selectively blocked extinction between Test 1 and Test 2, and is counter to the prediction of the reconsolidation hypothesis that anisomycin given after context reexposure should impair IA memory and thus result in shorter latencies at Test 2 .

The above results suggest that rats developed an extinction
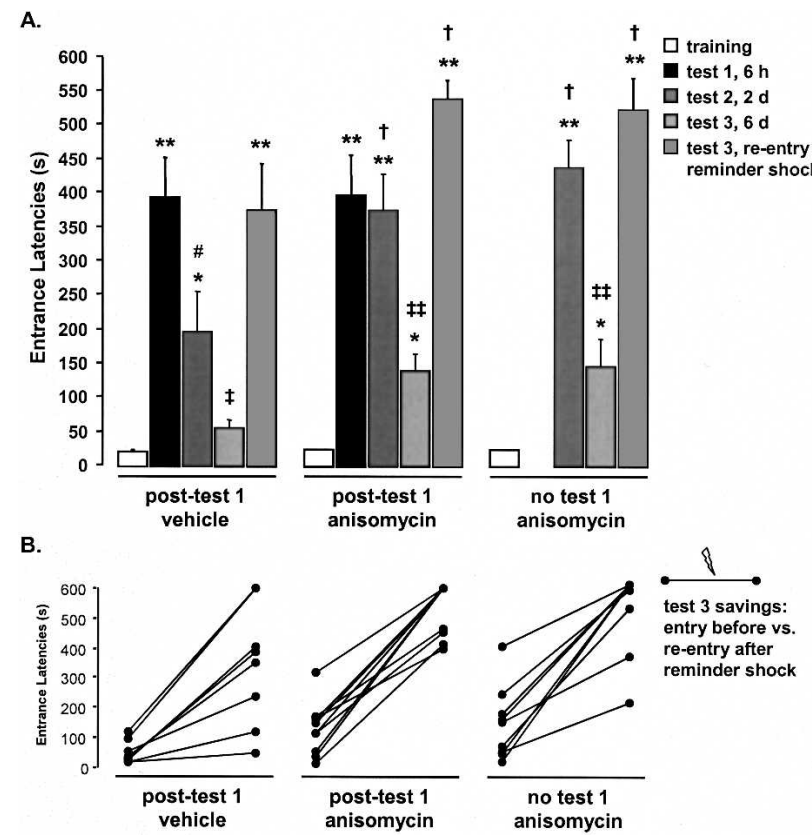

Figure 2. Extended re-exposure inhibitory avoidance behavior. Rats in Experiment 2 were left in the shock compartment for $200 \mathrm{sec}$ after entering it on the test days. Data are given as groups' mean latencies to cross into the shock context at each trial. (A) All groups learned to avoid the dark shock compartment $\left[\left(^{*}\right) P<0.05,\left({ }^{* *}\right) P<0.001\right.$ vs. training]. Vehicle controls showed extinction from Test 1 to Test $2[(\#) P<0.05$ vs. Test 1 within group] and from Test 2 to Test $3[(\ddagger) P<0.05$ vs. Test 2 within group]. Rats given anisomycin after Test 1 did not show extinction between Tests 1 and $2[P>0.05$ vs. Test 1 within group; $(\dagger) P<0.05$ vs. vehicle within trial], but did show subsequent extinction in the absence of the drug from Test 2 to Test 3 [( $\ddagger) P<0.001$ vs. Test 2 within group]. Anisomycin treatment without a Test 1 context re-exposure did not affect retention; however, these rats showed subsequent extinction in the absence of drug from Test 2 to Test $3[(\ddagger \ddagger) P<0.001$ vs. Test 2 within group]. The mild reminder shock given in Test 3 reinstated robust avoidance of the shock compartment in all groups, with the anisomycintreated groups showing greater avoidance after the reminder shock than the vehicle group $[(\dagger) P<0.05$ vs. vehicle within trial]. (B) The savings revealed by the mild reminder shock on day 6 in the individual rats of each group is shown.

memory following prolonged context re-exposure that competed with the initial IA training memory. An alternative explanation, however, is that the rats may simply have forgotten the initial training experience. To distinguish between these possibilities, rats in Experiment 2 received a mild reminder shock after entering the dark compartment during Test 3. This shock intensity in previously untrained rats is not sufficient to lead to the level of avoidance observed here during Test 1 . Thus if extinction had occurred, the reminder shock would fully restore the avoidance behavior observed at Test 1 , whereas if the training memory trace had been forgotten, then subsequent re-entrance latencies significantly shorter than those seen at Test 1 would be observed.

As illustrated in Figure 2, the mild reminder shock given during Test 3 reproduced highly significant avoidance of the shock compartment in all groups. Rats stopped walking or flinched in response to the reminder shock, but did not vocalize or jump as with the training shock. The mean re-entrance latency $(372 \pm 69 \mathrm{sec})$ for vehicle-treated rats after the reminder shock was similar to that observed at Test $1(P>0.05)$. Rats given anisomycin after Test 1 exhibited a mean re-entrance latency $(534 \pm 28 \mathrm{sec})$ after the reminder shock that was actually greater than that observed at Test $1(P<0.05)$. The magnitude of savings revealed by the reminder shock in individual rats is shown in 
Figure $2 \mathrm{~B}$. The average difference in latency after the reminder shock relative to before was $319 \pm 59 \mathrm{sec}$ for the vehicle group, $397 \pm 35 \mathrm{sec}$ for the post-Test 1 anisomycin group, and $374 \pm 51 \mathrm{sec}$ for the no-Test 1 anisomycin group $(P>0.05)$. All rats' retention latencies after the reminder shock were at least as great as their own latencies at Test 2 . These post-reminder retention scores reflect avoidance behavior far greater than that generally produced by the reminder shock alone (Power et al. 2003). Thus, the savings revealed during Test 3 confirmed that the rats developed a competing extinction memory from the reexposures to the context and did not simply forget the original training experience.

The retention performance at Test 2 of anisomycin-treated rats that were not re-exposed to the context $6 \mathrm{~h}$ after training $(433 \pm 40 \mathrm{sec})$ was not different from the Test 1 performance of rats given post-Test 1 vehicle or anisomycin infusions, or the Test 2 performance of rats given post-Test 1 anisomycin infusions (Ps $>0.05)$. Therefore, the extinction seen in the vehicle control group between Tests 1 and 2 required the context re-exposure 6 $\mathrm{h}$ after training. The no-Test 1 anisomycin-treatment control group had a mean retention latency at Test 3 (144 $\pm 40 \mathrm{sec})$ that was less than that at Test $2(P<0.001)$, demonstrating normal extinction between Tests 2 and 3 . And the reminder shock given during Test 3 reinstated avoidance of the shock compartment $(519 \pm 46 \mathrm{sec})$ that exceeded that seen with the vehicle-infused rats $(P<0.05)$. Overall, the behavioral data for Tests 2 and 3 were comparable for both anisomycin-treated groups (with or without context re-exposure at Test 1) in Experiment 2.

In summary, the extended re-exposure procedure used in Experiment 2 induced extinction learning. Anisomycin treatment given after Test 1 blocked extinction between Tests 1 and 2, but the same rats showed subsequent extinction in the absence of the drug treatment between Tests 2 and 3. The anisomycin treatment alone did not affect memory. The savings revealed by the reminder shock during Test 3 demonstrated that the rats did not forget the training experience between tests.

\section{Discussion}

Our experiments provide new insights into the proteinsynthesis-dependent processes triggered by a retention test. The key findings were that intrahippocampal infusion of anisomycin after the retention test disrupts subsequent retention performance if the exposure is brief and disrupts the extinction that would otherwise occur if the exposure is long enough to produce extinction. Importantly, the disruption of retention was temporary; retention was impaired $2 \mathrm{~d}$ after the retention test/ anisomycin, but recovered by $6 \mathrm{~d}$, indicating that the initial memory trace remained intact following anisomycin treatment. In what follows, we consider these conclusions in more detail.

\section{Post-retrieval retention performance impairment}

The first critical point is that we did, in fact, replicate the basic findings that led to the formulation of the reconsolidation hypothesis. When anisomycin was given after a retention test $6 \mathrm{~h}$ post-training, retention performance was impaired $2 \mathrm{~d}$ later, consistent with previous studies (Nader et al. 2000; Debiec et al. 2002; Milekic and Alberini 2002). It is noteworthy that the test/ retest interval used here $(6 \mathrm{~h})$ is shorter than in previous studies and is within a range that would permit analyses of physiological correlates of memory storage processes (i.e., LTP and LTD). The rats had a 6-h midday period between training and testing in which to engage in natural restful sleep, which may be important for long-term memory consolidation of the training (Louie and Wilson 2001; Power 2004; Vertes 2004; Walker and Stickgold 2004).
The mechanism of the post-retrieval retention deficit has not been resolved. Advocates of the reconsolidation hypothesis suggest that re-exposure triggers a new phase of memory lability and that a blockade of memory storage underlies the deficit (Nader et al. 2000; Debiec et al. 2002). If the impairment reflects a storage deficit, then the disruption should be permanent; memory should not return at subsequent tests (Duvarci and Nader 2004). However, consistent with several previous reports of recovery (Mactutus et al. 1979; Vianna et al. 2001; Anokhin et al. 2002; Bahar et al. 2004; Lattal and Abel 2004), we found that performance had recovered by $6 \mathrm{~d}$ after the anisomycin treatment. These findings are in conflict with the reconsolidation hypothesis, but are consistent with the alternative interpretations that such treatments may temporarily disrupt memory retrieval (Riccio et al. 2002; Arshavsky 2003; Lattal and Abel 2004) or enhance the expression of extinction (Fischer et al. 2004).

Recent studies have suggested that the degree of postretrieval retention performance impairment decreases as the delay between training and re-exposure is increased (Milekic and Alberini 2002; Suzuki et al. 2004). These findings suggest that susceptibility may be limited to recently acquired memories. Alternatively, it has been suggested that the stability of remote memories in the presence of anisomycin might be due to a progressive decrease in the period of protein synthesis dependence as systems level consolidation progresses, such that after about a week the necessary protein synthesis may be completed before systemically administered anisomycin can affect the brain (Nader 2003). If susceptibility to post-retrieval treatments is limited to relatively new memories, then the findings of selective impairment of recent memories (Milekic and Alberini 2002; Suzuki et al. 2004) should be reproducible with central administration of anisomycin. Moreover, because tests for spontaneous recovery of memory were not performed, it is not clear whether these memory age-dependent effects are permanent or may be the result of a temporary retrieval deficit (Lattal and Abel 2004).

\section{Blockade of extinction}

We replicated findings of post-test anisomycin-induced impaired extinction when rats were subjected to a longer context exposure during retention testing (Berman and Dudai 2001; Vianna et al. 2001; Lin et al. 2003; Santini et al. 2004). These findings are consistent with data suggesting that extinction learning engages a consolidation process similar to that involved in the original acquisition (Ledgerwood et al. 2003; Lin et al. 2003; Maruki et al. 2003; Sangha et al. 2003; Vianna et al. 2003; Bahar et al. 2004). The data are also consistent with an alternative hypothesis that retrieval of the extinction memory may have been impaired due to the memory being consolidated in the presence of anisomycin but tested in the absence of anisomycin. If this state-dependency hypothesis is true, then animals given anisomycin after a reexposure should show unimpaired extinction if subsequently tested under the influence of anisomycin. If protein synthesis inhibition had enhanced extinction in this experiment (Fischer et al. 2004), then the anisomycin-treated animals should have exhibited less avoidance (shorter latencies) than the vehicle controls. However, the Experiment 2 data were not consistent with that prediction.

The effects of the mild reminder shock given in Test 3 demonstrated savings from training and provided evidence that the rats had acquired a new extinction memory rather than having forgotten the training memory over time. The greater postreminder shock avoidance shown by the anisomycin-treated groups than that shown by the vehicle group is likely due to the vehicle group having had two extinction trials, whereas the anisomycin groups each effectively had only one.

\section{Learning \& Memory}




\section{Re-exposure duration-dependent effects of post-retrieval treatment}

As the rats in both paradigms received the same training and exhibited similar retention latencies at Test 1 , the only source for the divergence at Test 2 was the duration of the context reexposure during Test 1. Extinction was observed in rats given the extended, but not the brief, re-exposure. Thus, increasing context re-exposure such that it may support extinction learning may result in protein-synthesis-dependent extinction (Experiment 2) rather than a retrieved memory that is sensitive to the drug treatment (Experiments 1A and 1B).

In crabs trained in a danger cue-escape response conditioning task, the duration of re-exposure determines whether protein synthesis inhibition impairs retention performance or extinction (Pedreira and Maldonado 2003; Pedreira et al. 2004). Likewise, in a modified fear conditioning task in fish and conditioned taste aversion in rats, Eisenberg and colleagues (Eisenberg et al. 2003) found retention performance impairments only with more intensive training that did not result in single trial extinction. Here we found re-exposure time-dependent effects in a common rat paradigm in which only a single behavioral parameter was changed during the retrieval test. This convergence of findings suggests that whether one finds an effect on the memory for training or on extinction depends on the testing conditions used.

If a retrieved memory returns to a labile state (Nader 2003), it should be sensitive to the same neuromodulatory influences that affect newly acquired memories (McGaugh 2000; McIntyre et al. 2003). However, several post-retrieval test drug treatments have been found instead to enhance (McGaugh et al. 1990; Ledgerwood et al. 2003; Berlau and McGaugh 2004; Gonzalez-Lima and Bruchey 2004; Schroeder and Packard 2004) or to impair (Vianna et al. 2001; Maruki et al. 2003; Santini et al. 2004) extinction. These findings suggest that with re-exposure, memory consolidation processes engage in the storage of newly acquired information rather than in the "reconsolidation" of retrieved memory traces. However, Boccia et al. (2004) reported a postretrieval impairment with an anti-cholinergic drug similar to that of post-training cholinergic drug effects on consolidation (Power et al. 2003). Interestingly, this impairment was only seen in overtrained mice (Boccia et al. 2004), which is consistent with the present findings in suggesting that such impairments may only be seen in the absence of extinction.

The present findings indicate that post-retrieval administration of anisomycin impairs subsequent retention performance only in the absence of extinction and that this impairment is temporary. Thus, such impairment effects may occur only when the CS-US association is not weakened by the re-exposure. Consistent with the conclusions of Cammarota and colleagues (Cammarota et al. 2004b), who failed to demonstrate the "reconsolidation" effect under various training conditions, our findings do not support the hypothesis that retrieval of a memory trace induces it to become truly labile, as in immediately after learning, such that its storage can be blocked permanently with postreactivation manipulations. Indeed our findings failed to demonstrate permanent reconsolidation impairment with either the brief or the extended re-exposure duration. The mechanism underlying the temporary post-reactivation memory impairment and its significance for the neurobiology of memory remain to be elucidated.

\section{Materials and Methods}

\section{Subjects}

Sixty-nine male Sprague-Dawley rats (Harlan), weighing 300-325 $\mathrm{g}$ at the time of surgery, were used in these experiments. The rats were individually housed in a temperature-controlled $\left(22^{\circ} \mathrm{C}\right)$ vivarium on a 12-h light/12-h dark cycle, with food and water freely available, and were allowed 1 wk to habituate to the vivarium before surgery. The rats were allowed $1 \mathrm{wk}$ to recover from surgery before IA behavioral training. Rats were divided into three groups for Experiment 1A and Experiment 2: (1) post-Test 1 vehicle infusion, $n=9$; (2) post-Test 1 anisomycin, $n=10$; and (3) anisomycin infusion $6 \mathrm{~h}$ after training with no Test $1, n=9$. Experiment $1 \mathrm{~B}$ included only two groups: (1) post-Test 1 vehicle infusion, $n=5$, and (2) post-Test 1 anisomycin, $n=7$.

\section{Surgery}

For cannulae implantation, rats were anesthetized with sodium pentobarbitol $(50 \mathrm{mg} / \mathrm{kg}$, i.p.), and given atropine sulfate to maintain respiration $(0.1 \mathrm{mg} / 2 \mathrm{~mL}$, i.p.) and $0.9 \%$ sterile saline to prevent dehydration ( $2.5 \mathrm{~mL}$, s.c.). Cannulae (23 gauge) were implanted bilaterally above the dorsal hippocampus under stereotaxic guidance at $3.3 \mathrm{~mm}$ posterior and $1.5 \mathrm{~mm}$ lateral to Bregma, and $2.7 \mathrm{~mm}$ ventral to the skull surface (Paxinos and Watson 1998). The cannulae were fixed in place with dental cement and two anchoring surgical screws. After the surgery, 11mm-long stylets (\#00 insect dissection pins) were inserted into the cannulae to maintain patency. Rats were kept warm on heating pads until they awoke from the anesthesia. Rats were allowed $1 \mathrm{wk}$ to recover from the surgery before behavioral training and were handled on each of the $4 \mathrm{~d}$ preceding training to habituate them to the infusion procedure and maintain patent cannulae.

\section{Inhibitory avoidance task}

Our current understanding of the cellular and molecular processes that may underlie memory is based to a considerable extent on studies of synaptic correlates observed in acute neurophysiological experiments. Investigation of putative mechanisms of post-retrieval effects in acute in vivo or in vitro physiology experiments requires the establishment of a time frame compatible with both behavioral and physiological studies. With this goal in mind, we used a training to memory reactivation interval, $6 \mathrm{~h}$, that was just long enough to allow stabilization of the behavioral memory trace but also short enough to be applied in physiological studies. The IA paradigm is advantageous for studying memory consolidation because it includes a single discreet CS-US pairing during training.

The IA apparatus is a trough-shaped alley divided by a sliding door into two compartments: a lit safe compartment $(31 \mathrm{~cm}$ long) and a dark shock compartment (60 cm long). Rats were trained in the morning between 9:00 a.m. and 12:00 p.m. During training, each rat was placed into the lit safe compartment facing away from the dark compartment and allowed to enter and explore the dark shock compartment. After each rat stepped completely into the dark compartment with all four paws, the sliding door was closed and the animal received a single inescapable footshock $(0.6 \mathrm{~mA}, 2.0 \mathrm{sec})$. This intensity and duration of shock consistently caused rats to vocalize and jump. Rats remained in the dark compartment for $15 \mathrm{sec}$ following the shock and were then returned to their home cages.

Six hours after IA training, rats received a context reexposure and retention test (Test $1 ; 15: 00-18: 00$ h). Previous research indicates that long-term memory is stable by $6 \mathrm{~h}$ after training (Izquierdo and Medina 1997). During Test 1, each rat was placed in the lit safe compartment as in training. The latency for the rat to enter the dark shock compartment was recorded. The maximum latency cutoff was $600 \mathrm{sec}$. Retention was inferred from rats' hesitation to enter the shock compartment during the retention test. Any rat remaining in the lit start compartment after $600 \mathrm{sec}$ was gently guided into the dark compartment before being removed from the apparatus. As each rat moved completely into the dark compartment of the IA apparatus, the sliding door was closed behind it as in training. In Experiments $1 \mathrm{~A}$ and $1 \mathrm{~B}$, rats were then removed immediately from the dark compartment. In Experiment 2, rats were allowed to explore the dark compartment without receiving any shocks for $200 \mathrm{sec}$. Both 
Experiment 1A and Experiment 2 included a control group that remained in their home cages during the Test 1 period.

Forty-eight hours after training, avoidance of the dark shock compartment was tested again (Test 2). At Test 2, each rat was placed in the lit safe compartment as in training and Test 1 . The latency for the rat to enter the dark shock compartment was recorded. The maximum latency cutoff was $600 \mathrm{sec}$. As in Test 1, rats in Experiments 1A and 1B were removed from the dark compartment immediately upon entering it, whereas rats in Experiment 2 were allowed to explore the dark compartment for 200 sec in the absence of a footshock.

Six days after training, the rats in Experiment $1 \mathrm{~B}$ and Experiment 2 were subjected to a third test, during which they were placed in the lit safe compartment and again allowed to enter the dark shock compartment, and their latency to enter the dark shock compartment was recorded. To confirm that rats were exhibiting extinction between the test trials rather than forgetting, the rats received a mild reminder shock $(0.5 \mathrm{~mA}, 1 \mathrm{sec})$ in the shock compartment with the sliding door open during Test 3. Their latency to re-enter the shock compartment after the reminder shock was recorded. Cannulated rats that have received only a shock of the intensity and duration of this reminder shock exhibit mean retention latencies in the range of 50-100 sec (Power et al. 2003). The greater intensity and longer duration training shock used in the present experiments $(0.6 \mathrm{~mA}, 2 \mathrm{sec})$ produces far greater mean retention latencies than this reminder shock (Milekic and Alberini 2002). Thus, re-entrance latencies at Test 3 at least as great as that seen at Test 1 provide evidence for the presence of savings of the memory for the original training.

\section{Drug administration}

Immediately after Test 1 , rats received bilateral infusions of anisomycin (75 $\mu \mathrm{g} / \mathrm{side}$; Sigma) or vehicle (sterile physiological saline, $0.9 \%$ ) into the dorsal hippocampus. As a control for the drug effect alone, some rats were not given a Test 1 , but received similar anisomycin infusions $6 \mathrm{~h}$ after training. Anisomycin was initially dissolved in $3 \mathrm{~N} \mathrm{HCl}$ at $37^{\circ} \mathrm{C}$, and the solution was brought to a pH of 7.3 and a final concentration of $100 \mu \mathrm{g} / \mu \mathrm{L}$ by addition of $3 \mathrm{~N} \mathrm{NaOH}$ and sterile saline. The drug solution was prepared fresh on each infusion day. Rats received $0.75 \mu \mathrm{L}$ of this solution through each guide cannula immediately after Test 1 . This anisomycin solution is similar to that used in previous reports (Quevedo et al. 1999; Vianna et al. 2001, 2003). Solutions were infused slowly into the hippocampus over $90 \mathrm{sec}$ by an automated syringe pump (Sage Instruments) via 30-gauge injection needles $(12.5 \mathrm{~mm})$ attached to $10-\mu \mathrm{L}$ Hamilton microsyringes by PE-20 polyethylene tubing. The infusion needles extended $1.5 \mathrm{~mm}$ beyond the guide cannulae and were left in place for an additional $90 \mathrm{sec}$ after the infusions to allow diffusion into the hippocampus. Following the drug or vehicle infusions, the rats were replaced into their home cages.

\section{Histology}

After completion of behavioral testing, rats were anesthetized with an overdose of sodium pentobarbital and perfused intracardially with phosphate buffered saline (PBS) (pH 7.4). Brains were removed and immersed in fresh $4 \%$ paraformaldehyde and then were transferred to a $25 \%$ sucrose in PBS solution for cryoprotection. Forty-micrometer coronal sections through the hippocampus were cut on a freezing microtome, mounted on gelatincoated slides, and Nissl-stained with thionin. The sections were examined under a light microscope, and the loci of the infusion needle tracks were determined according to the standardized atlas of Paxinos and Watson (1998) by an observer blind to group designation. Only rats with both needle tracks terminating within the dorsal hippocampus were included in the behavioral analysis. The loci of the infusion needle tips for all subjects (final $n=69$ ) are summarized in Figure 3.

\section{Statistical analysis}

The behavioral data are reported as mean entrance latencies with the standard errors of the mean. Rats showed a normal distribution in their avoidance behavior. Data from each experiment were analyzed with a two-way analysis of variance (ANOVA) with treatment group as a between-subject variable and trial as a within-subject variable (training, Test 1 and Test 2 for all experiments as well as Test 3 and Test 3 re-entry for Experiment $1 \mathrm{~B}$ and Experiment 2). Fisher's multiple comparisons post hoc tests were used to detect the sources of the significances detected by the
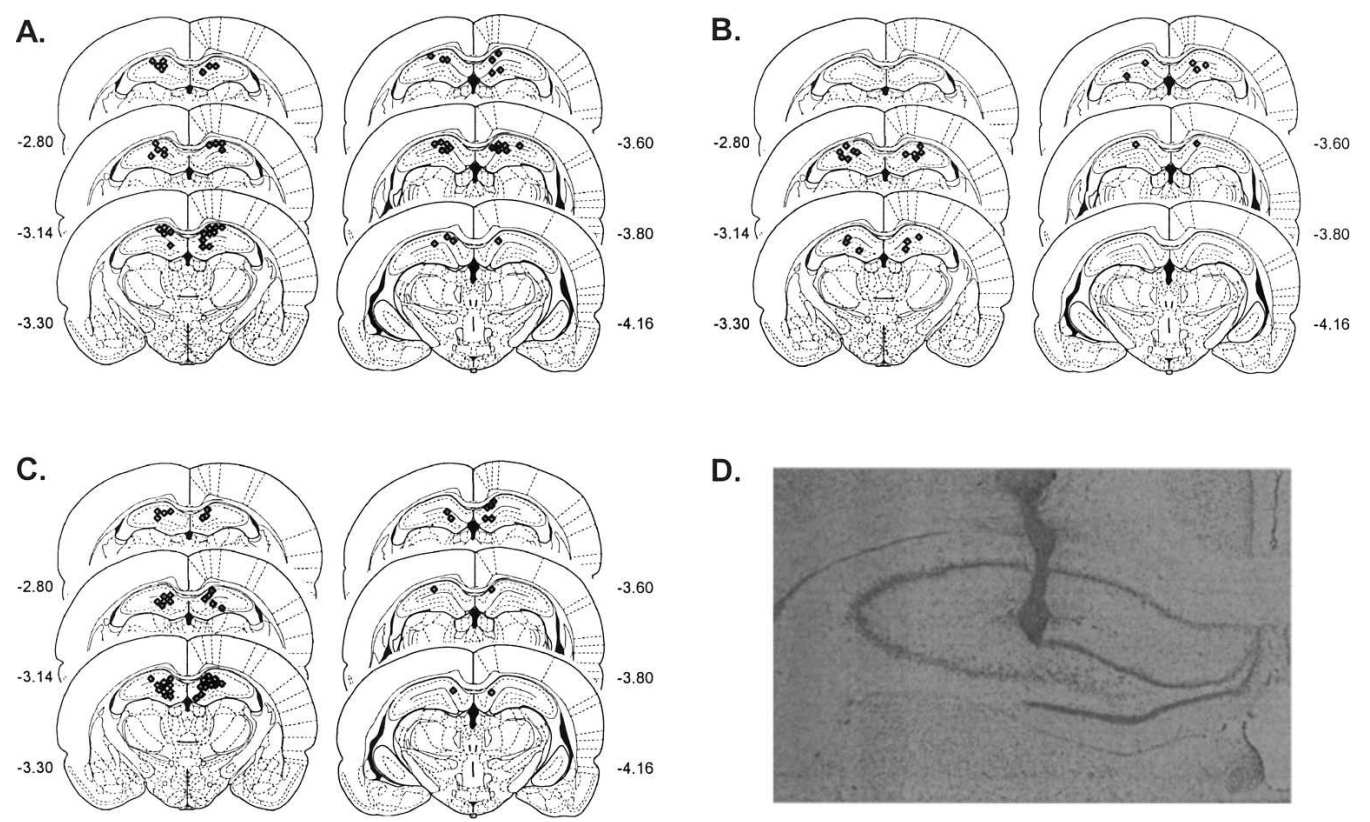

Figure 3. All rats represented in the behavioral data were confirmed to have infusion sites located within the dorsal hippocampus as shown in $A$ for in Experiment 1A $(n=28), B$ for Experiment 1B $(n=12)$, and C for Experiment $2(n=28)$. (D) A representative example of an intrahippocampal infusion site. Coordinates are given as millimeters posterior to Bregma. Coronal section plates were adapted with permission from Elsevier $\odot$ 1998, Paxinos and Watson (1998).

\section{Learning \& Memory}

www.learnmem.org 
ANOVAs. In all cases, comparisons with $P$-values $<0.05$ were considered significant.

\section{Acknowledgments}

This research was funded by a NIH Research Grant from the NINDS, NS12333 (to O.S.) and a NIH Research Grant from the NIMH, MH12526 (to J.L.M.). We thank Bryant Tran for his valuable technical assistance.

\section{References}

Alberini, C. 2005. Mechanisms of memory stabilization: Are consolidation and reconsolidation similar or distinct processes? Trends Neurosci. 28: 51-56.

Anokhin, K.V., Tiunova, A.A., and Rose, S.P.R. 2002. Reminder effects-Reconsolidation or retrieval deficit? Pharmacological dissection with protein synthesis inhibitors following reminder for a passive-avoidance task in young chicks. Eur. J. Neurosci. 15: 1759-1765.

Arshavsky, Y.L. 2003. Long-term memory: Does it have a structural or chemical basis? Trends Neurosci. 26: 465-466.

Bahar, A., Samuel, A., and Dudai, Y. 2003. The amygdalar circuit that acquires taste aversion memory differs from the circuit that extinguishes it. Eur. J. Neurosci. 17: 1527-1530.

Bahar, A., Dorfman, N., and Dudai, Y. 2004. Amygdalar circuits required for either consolidation or extinction of taste aversion memory are not required for reconsolidation. Eur. J. Neurosci. 19: 1115-1118.

Barrientos, R.M., O’Reilly, R.C., and Rudy, J.W. 2002. Memory for context is impaired by injecting anisomycin into dorsal hippocampus following context exploration. Behav. Brain Res. 134: 299-306.

Berlau, D.J. and McGaugh, J.L. 2004. Infusions of the GABA antagonist bicuculline into the basolateral amygdala enhance extinction of contextual fear conditioning. Soc. Neurosci. Abs. 34: 327.3.

Berman, D.E. and Dudai, Y. 2001. Memory extinction, learning anew, and learning the new: Dissociations in the molecular machinery of learning in cortex. Science 291: 2417-2419.

Biedenkapp, J.C. and Rudy, J.W. 2004. Context memories and reactivation: Constraints on the reconsolidation hypothesis. Behav. Neurosci. 118: 956-964.

Boccia, M.M., Acosta, G.B., Blake, M.G., and Baratti, C.M. 2004 Memory consolidation and reconsolidation of an inhibitory avoidance response in mice: Effects of i.c.v. injections of hemicholinium-3. Neuroscience 124: 735-741.

Bouton, M.E. 2004. Context and behavioral processes in extinction. Learn. Mem. 11: 485-494.

Bozon, B., Davis, S., and Laroche, S. 2003. A requirement for the immediate early gene zif268 in reconsolidation of recognition memory after retrieval. Neuron 40: 695-701.

Cammarota, M., Barros, D.M., Vianna, M.R., Bevilaqua, L.R., Coitinho, A., Szapiro, G., Izquierdo, L.A., Medina, J.H., and Izquierdo, I. 2004a. The transition from memory retrieval to extinction. An. Acad. Braz. Cienc. 76: 573-582.

Cammarota, M., Bevilaqua, L.R., Medina, J.H., and Izquierdo, I. 2004b. Retrieval does not induce reconsolidation of inhibitory avoidance memory. Learn. Mem. 11: 572-578.

Davis, H.P. and Squire, L.R. 1984. Protein synthesis and memory: A review. Psychol. Bull. 96: 518-559.

Dawson, R.G. and McGaugh, J.L. 1969. Electroconvulsive shock effects on a reactivated memory trace: Further examination. Science 166: $525-527$.

Debiec, J., LeDoux, J.E., and Nader, K. 2002. Cellular and systems reconsolidation in the hippocampus. Neuron 36: 527-538.

DeVietti, T.L. and Holliday, J.H. 1972. Retrograde amnesia produced by electroconvulsive shock after reactivation of a consolidated memory trace: A replication. Psychon. Sci. 29: 137-138.

Dudai, Y. 2004. The neurobiology of consolidations, or, how stable is the engram? Annu. Rev. Psych. 55: 51-86.

Duvarci, S. and Nader, K. 2004. Characterization of fear memory reconsolidation. J. Neurosci. 24: 9269-9275.

Eisenberg, M., Kobilo, T., Berman, D.E., and Dudai, Y. 2003. Stability of retrieved memory: Inverse correlation with trace dominace. Science 301: 1102-1104.

Fischer, A., Sananbenesi, F., Schrick, C., Spiess, J., and Radulovic, J. 2004. Distinct roles of hippocampal de novo protein synthesis and actin rearrangement in extinction of contextual fear. J. Neurosci. 24: 1962-1966.

Gonzalez-Lima, F. and Bruchey, A.K. 2004. Extinction memory improvement by metabolic enhancer methylene blue. Learn. Mem. 11: $633-640$.
Izquierdo, I. and Medina, J.H. 1997. Memory formation: The sequence of biochemical events in the hippocampus and its connection to activity in other brain structures. Neurobiol. Learn. Mem. 68: $285-316$.

Kelly, A., Larcohe, S., and Davis, S. 2003. Activation of mitogen-activated protein kinase/extracellular signal-regulated kinase in hippocampal circuitry is required for consolidation and reconsolidation of recognition memory. J. Neurosci. 23: 5354-5360.

Kida, S., Josselyn, S.A., de Ortiz, S.P., Kogan, J.H., Chevere, I., Masushige, S., and Silva, A.J. 2002. CREB required for the stability of new and reactivated fear memories. Nat. Neurosci. 5: 348-355.

Koh, M.T. and Bernstein, I.L. 2003. Inhibition of protein kinase A activity during conditioned taste aversion retrieval: Interference with extinction or reconsolidation or a memory. NeuroReport 14: 405-407.

Lattal, K.M. and Abel, T. 2004. Behavioral impairments caused by injections of the protein synthesis inhibitor anisomysin after contextual retrieval reverse with time. Proc. Natl. Acad Sci. 101: 4667-4672.

Lattal, K.M., Honarvar, S., and Abel, T. 2004. Effects of post-session injections of anisomycin on the extinction of a spatial preference and on the acquisition of a spatial reversal preference. Behav. Brain Res. 153: 327-339.

Ledgerwood, L., Richardson, R., and Cranney, J. 2003. Effects of D-cycloserine on extinction of conditioned freezing. Behav. Neurosci. 117: 341-349.

Lee, J.L.C., Everitt, B.J., and Thomas, K.L. 2004. Independent cellular processes for hippocampal memory consolidation and reconsolidation. Science 304: 839-843.

Lewis, D.J. 1979. Psychobiology of active and inactive memory. Psychol. Bull. 86: 1054-1083.

Lin, C.-H., Yeh, S.-H., Lu, H.-Y., and Gean, P.-W. 2003. The similarities and diversities of signal pathways leading to consolidation of conditioning and consolidation of extinction of fear memory. $J$. Neurosci. 23: 8310-8317.

Louie, K. and Wilson, M.A. 2001. Temporally structured replay of awake hippocampal ensemble activity during rapid eye movement sleep. Neuron 29: 145-156.

Mactutus, C.F., Riccio, D.C., and Ferek, J.M. 1979. Retrograde amnesia for old (reactivated) memory: Some anomalous characteristics. Science 204: 1319-1320.

Maruki, K., Izaki, Y., Akema, T., and Nomura, M. 2003. Effects of acetylcholine antagonist injection into the prefrontal cortex on the progress of lever-press extinction in rats. Neurosci. Lett. 351: 95-98.

McGaugh, J.L. 1966. Time-dependent processes in memory storage. Science 153: 1351-1358.

. 2000. Memory-A century of consolidation. Science 287: $248-251$.

. 2004. Memory reconsolidation hypothesis revived but restrained: Theoretical comment on Biedenkapp and Rudy. Behav. Neurosci. 118: 1140-1142.

McGaugh, J.L., Castellano, C., and Brioni, J.D. 1990. Picrotoxin enhances latent extinction of conditioned fear. Behav. Neurosci. 104: $262-265$.

McIntyre, C.K., Power, A.E., Roozendaal, B., and McGaugh, J.L. 2003. Role of the basolateral amygdala in memory consolidation. Ann. NY Acad. Sci. 985: 273-293.

Milekic, M.H. and Alberini, C.M. 2002. Temporally graded requirement for protein synthesis following memory reactivation. Neuron 36: $521-525$.

Mingote, S., de Bruin, J.P.C., and Feenstra, M.G.P. 2004. Noradrenaline and dopamine efflux in the prefrontal cortex in relation to appetitive classical conditioning. J. Neurosci. 24: 2475-2480.

Misanin, J.R., Miller, R.R., and Lewis, D.J. 1968. Retrograde amnesia produced by electroconvulsive shock after reactivation of a consolidated memory trace. Science 160: 554-555.

Nader, K. 2003. Memory traces unbound. Trends Neurosci. 26: 65-72.

Nader, K., Schafe, G.E., and LeDoux, J.E. 2000. Fear memories require protein synthesis in the amygdala for reconsolidation after retrieval. Nature 406: 722-726.

Pavlov, I.P. 1927. Conditioned reflexes: An investigation of the physiological activity of the cerebral cortex. Oxford University Press, London.

Paxinos, G. and Watson, C. 1998. The rat brain in stereotaxic coordinates. Academic Press, San Diego, CA.

Pedreira, M.E. and Maldonado, H. 2003. Protein synthesis subserves reconsolidation or extinction depending on reminder duration. Neuron 38: 863-869.

Pedreira, M.E., Pérez-Cuesta, L.M., and Maldonado, H. 2004. Mismatch between what is expected and what actually occurs triggers memory reconsolidation or extinction. Learn Mem. 11: 579-585.

Power, A.E. 2004. Slow-wave sleep, acetylcholine, and memory consolidation. Proc. Natl. Acad. Sci. 101: 1795-1796.

Power, A.E., Vazdarjanova, A., and McGaugh, J.L. 2003. Muscarinic 
cholinergic influences in memory consolidation. Neurobiol. Learn. Mem. 80: 178-193.

Przybyslawski, J. and Sara, S.J. 1997. Reconsolidation of memory after its reactivation. Behav. Brain Res. 84: 241-246.

Quevedo, J., Vianna, M.R.M., Roesler, R., de-Paris, F., Izquierdo, I., and Rose, S.P.R. 1999. Two time windows of anisomycin-induced amnesia for inhibitory avoidance training in rats: Protection from amnesia by pretraining but not pre-exposure to the task apparatus. Learn. Mem. 6: 600-607.

Riccio, D.C., Moody, E.W., and Millin, P.M. 2002. Reconsolidation reconsidered. Integr. Physiol. Behav. Sci. 37: 245-253.

Salinska, E., Bourne, R.C., and Rose, S.P. 2004. Reminder effects: The molecular cascade following a reminder in young chicks does not recapitulate that following training on a passive avoidance task. Eur. J. Neurosci. 19: 3042-3047.

Sangha, S., Scheibenstock, A., Morrow, R., and Lukowiak, K. 2003. Extinction requires new RNA and protein synthesis and the soma of the cell right pedal dorsal 1 in Lymnaea stagnalis. J. Neurosci. 23: 9842-9851.

Santini, E., Ge, H., Ren, K., Peña de Ortiz, S., and Quirk, G.J. 2004. Consolidation of fear extinction requires protein synthesis in the medial prefrontal cortex. J. Neurosci. 24: 5704-5710.

Sara, S.J. 2000. Strengthening the shaky trace through retrieval. Nat. Rev. Neurosci. 1: 212-213.

Schneider, A.M. and Sherman, W. 1968. Amnesia: A function of the temporal relation of footshock to electroconvulsive shock. Science 159: $219-221$.
Schroeder, J.P. and Packard, M.G. 2004. Facilitation of memory for extinction of drug-induced conditioned reward: Role of amygdala and acetylcholine. Learn. Mem. 11: 641-647.

Strekalova, T., Zörner, B., Zacher, C., Sadovska, G., Herdegen, T., and Gass, P. 2003. Memory retrieval after contextual fear conditioning induces c-Fos and JunB expression in CA1 hippocampus. Genes Brain Behav. 2: 3-10.

Suzuki, A., Josselyn, S.A., Frankland, P.W., Masushige, S., Silva, A.J., and Kida, S. 2004. Memory reconsolidation and extinction have distinct temporal and biochemical signatures. J. Neurosci. 24: 4787-4795.

Taubenfeld, S.M., Milekic, M.H., Monti, B., and Alberini, C.M. 2001. The consolidation of new but not reactivated memory requires hippocampal C/EPB $\beta$. Nat. Neurosci. 4: 813-818.

Vertes, R.P. 2004. Memory consolidation in sleep; dream or reality. Neuron 44: $135-148$.

Vianna, M.R.M., Szapiro, G., McGaugh, J.L., Medina, J.H., and Izquierdo, I. 2001. Retrieval of memory for fear-motivated training initiates extinction requiring protein synthesis in the rat hippocampus. Proc. Natl. Acad. Sci. 98: 12251-12254.

Vianna, M.R., Igaz, L.M., Coitinhi, A.S., Medina, J.H., and Izquierdo, I. 2003. Memory extinction requires gene expression in rat hippocampus. Neurobiol. Learn. Mem. 79: 199-203.

Walker, M.P. and Stickgold, R. 2004. Sleep-dependent learning and memory consolidation. Neuron 44: 121-133.

Received December 27, 2004; accepted in revised form November 3, 2005.

\section{Learning \& Memory}




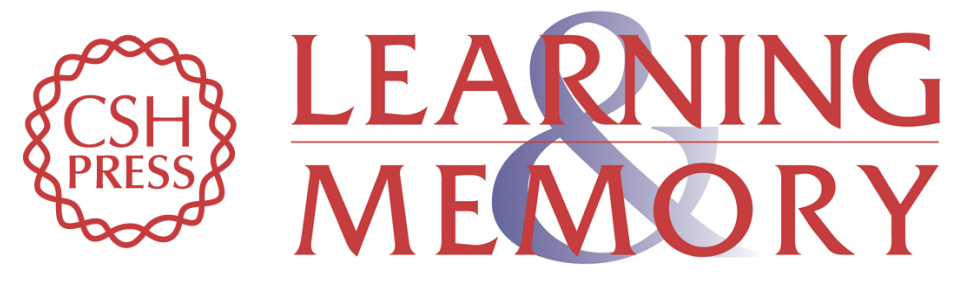

\section{Anisomycin infused into the hippocampus fails to block "reconsolidation" but impairs extinction: The role of re-exposure duration}

Ann E. Power, Daniel J. Berlau, James L. McGaugh, et al.

Learn. Mem. 2006, 13:

Access the most recent version at doi:10.1101//m.91206

References This article cites 66 articles, 26 of which can be accessed free at:

http://learnmem.cshlp.org/content/13/1/27.full.html\#ref-list-1

License

Email Alerting

Receive free email alerts when new articles cite this article - sign up in the box at the Service top right corner of the article or click here. 